\title{
New Generation Neonatal High Frequency Ventilators: Effect of Oscillatory Frequency and Working Principles on Performance
}

\author{
Serge Grazioli MD, Oliver Karam MSc MD, and Peter C Rimensberger MD
}

\begin{abstract}
BACKGROUND: Several new generation neonatal ventilators that incorporate conventional as well as high frequency ventilation (HFOV) have appeared on the market. Most of them offer the possibility to use HFOV in a volume-targeted mode, despite absence of any preclinical data. With a bench test, we evaluated the performances of 4 new neonatal HFOV devices and compared them to the SensorMedics HFOV device. METHODS: Expiratory tidal volumes $\left(V_{T}\right)$ were measured for various ventilator settings and lung characteristics (ie, modifications of compliance and resistance of the system), to mimic several clinical conditions of pre-term and term infants. RESULTS: Increasing the frequency proportionally decreased the $V_{T}$ for all the ventilators, although the magnitude of the decrease was highly variable between ventilators. At $15 \mathrm{~Hz}$ and a pressure amplitude of $60 \mathrm{~cm} \mathrm{H} \mathrm{H}_{2} \mathrm{O}$, the delivered $\mathrm{V}_{T}$ ranged from 3.5 to $5.9 \mathrm{~mL}$ between devices while simulating pre-term infant conditions and from 2.6 to $6.3 \mathrm{~mL}$ while simulating term infant conditions. Activating the volume-targeted mode in the 3 machines that offer this mode allowed the $V_{T}$ to remain constant over the range of frequencies and with changes of lung mechanical properties, for pre-term infant settings only while targeting a $V_{T}$ of $1 \mathrm{~mL}$. CONCLUSIONS: These new generation neonatal ventilators were able to deliver adequate $V_{T}$ under pre-term infant, but not term infant respiratory system conditions. The clinical relevance of these findings will need to be determined by further studies. Key words: high frequency ventilation; neonatal intensive care; respiratory mechanics; volume-targeted ventilation. [Respir Care 2015;60(3):363-370. (C) 2015 Daedalus Enterprises]
\end{abstract}

\section{Introduction}

The clinical use of high frequency oscillatory ventilation (HFOV) in pre-term infants remains controversial, as previous meta-analysis failed to show a significant difference between HFOV and conventional mechanical ventilation in mortality, bronchopulmonary dysplasia, and adverse neurological outcomes. ${ }^{1,2}$ However, some studies that initiated HFOV very early in pre-term infants with

The authors are affiliated with the Neonatal and Pediatric Intensive Care Unit, University Hospital of Geneva, Switzerland.

The authors have disclosed no conflicts of interest.

Correspondence: Peter C Rimensberger MD, Neonatal and Pediatric Intensive Care Unit, Department of Pediatrics, University Hospital of Geneva, Rue Willy Donzé 6, 1211 Geneva 14, Switzerland. E-mail: peter.rimensberger@hcuge.ch.

DOI: $10.4187 /$ respcare. 03048 respiratory distress syndrome have shown that surfactant doses, ventilator days, and chronic lung diseases could be reduced compared with conventional mechanical ventilation. ${ }^{1,3,4}$ Therefore, the concept of using HFOV as a primary ventilation mode in infants presenting with respiratory distress syndrome of various origins remains of interest.

Accordingly, several manufacturers have introduced new neonatal HFOV devices on the market. These new devices, including the Babylog VN500 (Dräger Medical, Lübeck, Germany), the Fabian HFO (Acutronic Medical System, Hirzel, Switzerland), the SLE 5000 (SLE, South Croydon, United Kingdom), and the Leoni Plus (Heinen+ Löwenstein, Bad Ems, Germany) offer both conventional mechanical ventilation and HFOV as ventilation modes. In addition, a new concept of $\mathrm{V}_{\mathrm{T}}$ targeting during HFOV has been introduced in 3 of them (Babylog VN500, Fabian HFO, and Leoni Plus), despite the absence of any clinical data on volume targeting high frequency oscillation. Recently, one experimental study investigated the stability of $\mathrm{P}_{\mathrm{CO}_{2}}$ during HFOV using the volume guarantee mode, 
showing that $\mathrm{P}_{\mathrm{CO}_{2}}$ remained stable with maintenance of minute ventilation during HFOV before and after surfactant depletion in piglets. ${ }^{5}$

The technical features added to these new ventilators, in particular the choice of the ventilator mode between conventional mechanical ventilation and HFOV, the measurements of $\mathrm{V}_{\mathrm{T}}$, and the volume-targeted mode during HFOV might represent all attractive features for the clinician, but data on volume delivery accuracy and performance of these new generation HFOV devices are lacking. Most of the published data on mechanical performance of oscillatory ventilators dates back more than $10 \mathrm{y},{ }^{6-8}$ and there is only one recent study, which looked into the performance of the Babylog VN500, showing a reduction of its power for generating oscillatory pressure amplitudes at higher operating frequencies. ${ }^{9}$ Furthermore, published data on stability of $\mathrm{V}_{\mathrm{T}}$ during volume-targeted ventilation are conflicting. ${ }^{10,11}$ Our group found, in a bench study ${ }^{12}$ on volume-targeted ventilation during conventional mechanical ventilation significant differences between set $\mathrm{V}_{\mathrm{T}}$ and delivered $\mathrm{V}_{\mathrm{T}}$ among the tested neonatal ventilators under changes in respiratory mechanics. Given these unknowns, we aimed to evaluate the performances of several new neonatal HFOV devices at various oscillations frequencies and in various respiratory system conditions, with and without the volume targeting mode activated.

Therefore, our hypothesis was that the new neonatal HFOV devices would perform similarly to the SensorMedics 3100A (CareFusion, San Diego, California), with and without the volume targeting mode activated, and in various lung conditions.

\section{Methods}

We studied 4 neonatal ventilators offering both HFOV and conventional mechanical ventilation modes: the Baby$\log$ VN500, the Fabian HFO, the SLE 5000, and the Leoni Plus (Table 1). As reference device for comparisons, we used the well-established SensorMedics 3100A.

\section{Experimental Set-Up}

The ventilators were equipped with the same commercially available standard neonatal respiratory circuit (single-use neonatal respiratory circuit, Fisher \& Paykel Healthcare, Auckland, New Zealand) with the exception of the SLE 5000 and the SensorMedics 3100A, which can only operate a unique circuit supplied by the manufacturer. The humidification chamber was kept in line but run dry with no heating. The continuous bias flow was (1) automatically modulated for the Babylog VN500, (2) delivered at a constant flow at $8 \mathrm{~L} / \mathrm{min}$ for the SLE 5000 and $7 \mathrm{~L} / \mathrm{min}$ for the Leoni Plus, (3) set at $20 \mathrm{~L} / \mathrm{min}$ at the

\section{QUICK LOOK}

\section{Current knowledge}

The clinical use of high frequency oscillatory ventilation (HFOV) in preterm infants remains controversial as meta-analysis failed to show a significant difference versus conventional ventilation with respect to mortality, bronchopulmonary dysplasia, and adverse neurological outcomes. Despite the unproven utility, a number of conventional ventilators with an HFOV option have been introduced.

\section{What this paper contributes to our knowledge}

Neonatal HFOV ventilators deliver adequate oscillation tidal volume $(1 \mathrm{~mL} / \mathrm{kg})$ under bench test conditions simulating respiratory system mechanics of a pre-term infant and maintain tidal volume constant in the volume-targeted mode. However, not all of the ventilators could deliver adequate oscillation tidal volume $(4 \mathrm{~mL} / \mathrm{kg}$ ) for term infant conditions.

maximal value possible for the Fabian HFOV, and (4) set at $20 \mathrm{~L} / \mathrm{min}$ per our guidelines for the SensorMedics 3100A.

The ventilators were connected to the $8.0-\mathrm{mm}$ internal diameter tube of a neonatal test lung (model 1601, Michigan Instruments, Grand Rapids, Michigan) (Fig. 1). Compliance was adjusted on the test lung, and airway resistance was simulated using different airway resistors, which allowed comparison of the performance of the ventilators in various respiratory system conditions. To simulate the mechanical proprieties of the respiratory systems of a full-term infant (with an assumed body weight of $4 \mathrm{~kg}$ ), we used a resistance of $70 \mathrm{~cm} \mathrm{H}_{2} \mathrm{O} / \mathrm{L} / \mathrm{s}$ with compliance of $4 \mathrm{~mL} / \mathrm{cm} \mathrm{H}_{2} \mathrm{O}$; to simulate a pre-term infant (with an assumed body weight of $1 \mathrm{~kg}$ ), we used a resistance of $100 \mathrm{~cm} \mathrm{H}_{2} \mathrm{O} / \mathrm{L} / \mathrm{s}$ with compliance of $2 \mathrm{~mL} / \mathrm{cm} \mathrm{H}_{2} \mathrm{O}$ as a baseline settings. The expiratory $\mathrm{V}_{\mathrm{T}}$ was measured with the Florian neonatal respiratory monitor (Acutronic Medical System), which has been validated for measurements of very small $\mathrm{V}_{\mathrm{T}}$ during HFOV. ${ }^{13}$ The Florian's flow sensor was positioned at the Y-piece and was calibrated according to the manufacturer's instructions before each test series. Mean airway pressure $\left(\overline{\mathrm{P}}_{\mathrm{aw}}\right)$ and oscillation pressure amplitude $\left(\Delta \mathrm{P}_{\text {vent }}\right)$ were measured by the ventilator's transducer inserted between the ventilator and the Y-piece and recorded as displayed by the ventilator. For each of the 5 ventilators, the same operator recorded single measurements manually after the system had reached a steady state, with no more changes in the readout after a minimum of $1 \mathrm{~min}$. 
Table 1. Characteristics of Tested Ventilators

\begin{tabular}{|c|c|c|c|c|c|}
\hline & SensorMedics 3100A & Babylog VN500 & Fabian HFO & Leoni Plus & SLE 5000 \\
\hline Manufacturer & CareFusion & Dräger & Acutronic & Heinen +Löwenstein & SLE \\
\hline Technical principles & $\begin{array}{l}\text { Oscillations generated } \\
\text { by a large } \\
\text { loudspeaker }\end{array}$ & $\begin{array}{l}\text { Servo valve controlled } \\
\text { pulsed inspiratory } \\
\text { flow Expiratory valve } \\
\text { oscillation }\end{array}$ & Membrane oscillation & Membrane oscillation & $\begin{array}{l}\text { Opposing flow at the } \\
\text { expiratory manifold }\end{array}$ \\
\hline Mode & HFOV & $\begin{array}{c}\text { Conventional mechanical } \\
\text { ventilation and HFOV }\end{array}$ & $\begin{array}{c}\text { Conventional mechanical } \\
\text { ventilation and HFOV }\end{array}$ & $\begin{array}{l}\text { Conventional mechanical } \\
\text { ventilation and HFOV }\end{array}$ & $\begin{array}{l}\text { Conventional mechanical } \\
\text { ventilation and HFOV }\end{array}$ \\
\hline $\begin{array}{l}\text { Volume-targeted } \\
\text { mode }\end{array}$ & $\begin{array}{l}\text { No volume-targeted } \\
\text { mode }\end{array}$ & $\begin{array}{l}\text { Volume-targeted mode } \\
\text { in HFOV }\end{array}$ & $\begin{array}{l}\text { Volume-targeted mode in } \\
\text { HFOV }\end{array}$ & $\begin{array}{l}\text { Volume-targeted mode } \\
\text { in HFOV }\end{array}$ & $\begin{array}{l}\text { No volume-targeted } \\
\text { mode in HFOV }\end{array}$ \\
\hline $\mathrm{V}_{\mathrm{T}}$ monitoring & No $\mathrm{V}_{\mathrm{T}}$ monitoring & Hot-wire anemometer & Hot-wire anemometer & Hot-wire anemometer & Hot-wire anemometer \\
\hline Flow & $0-40 \mathrm{~L} / \mathrm{min}$ & $2-30 \mathrm{~L} / \mathrm{min}$ & $1-20 \mathrm{~L} / \mathrm{min}$ & $7 \mathrm{~L} / \mathrm{min}$ & $8 \mathrm{~L} / \mathrm{min}$ \\
\hline $\begin{array}{l}\text { Pressure amplitude } \\
\text { setting range }\end{array}$ & $1-90 \mathrm{~cm} \mathrm{H}_{2} \mathrm{O}$ & $1-90 \mathrm{~cm} \mathrm{H}_{2} \mathrm{O}$ & $5-80 \mathrm{~cm} \mathrm{H}_{2} \mathrm{O}$ & $0-100 \mathrm{~cm} \mathrm{H}_{2} \mathrm{O}$ & 4-180 $\mathrm{cm} \mathrm{H}_{2} \mathrm{O}$ \\
\hline $\begin{array}{l}\text { Mean pressure } \\
\text { setting range }\end{array}$ & $3-45 \mathrm{~cm} \mathrm{H}_{2} \mathrm{O}$ & $5-50 \mathrm{~cm} \mathrm{H}_{2} \mathrm{O}$ & $5-50 \mathrm{~cm} \mathrm{H}_{2} \mathrm{O}$ & $0-40 \mathrm{~cm} \mathrm{H}_{2} \mathrm{O}$ & $0-35 \mathrm{~cm} \mathrm{H}_{2} \mathrm{O}$ \\
\hline $\begin{array}{l}\text { Frequency setting } \\
\text { range }\end{array}$ & $3-15 \mathrm{~Hz}$ & $5-20 \mathrm{~Hz}$ & $5-20 \mathrm{~Hz}$ & $5-20 \mathrm{~Hz}$ & $3-20 \mathrm{~Hz}$ \\
\hline $\begin{array}{l}\text { Inspiratory/expiratory } \\
\text { ratios }\end{array}$ & $1: 1$ and $1: 2$ & $1: 1$ to $1: 3$ & $1: 1$ to $1: 3$ & $1: 1$ to $1: 3$ & $1: 1$ \\
\hline
\end{tabular}

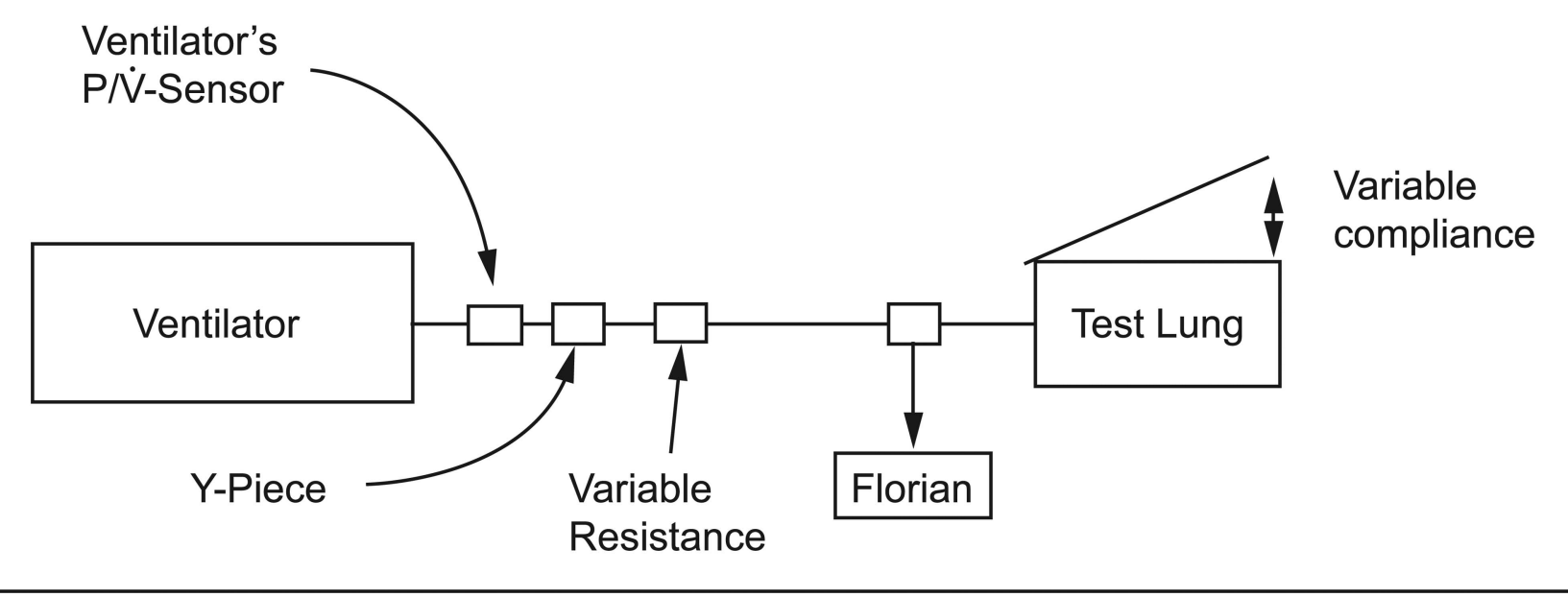

Fig. 1. Diagram of the experimental setup of the test lung. P/V-sensor $=$ pressure/flow sensor.

\section{Study Protocol}

We compared the expiratory $\mathrm{V}_{\mathrm{T}}$ at different oscillatory frequencies $(5,10$, and $15 \mathrm{~Hz})$ and at increasing $\Delta \mathrm{P}_{\text {vent }}$ (30, $45,60 \mathrm{~cm} \mathrm{H} \mathrm{H}_{2} \mathrm{O}$ and maximal $\Delta \mathrm{P}_{\text {vent }}$ offered by the ventilator) in full-term and pre-term infant settings. The $\overline{\mathrm{P}}_{\mathrm{aw}}$ was set at $15 \mathrm{~cm} \mathrm{H}_{2} \mathrm{O}$, and the I-E ratio was set at 1:1. To simulate restrictive lung disease, the compliance was modified from 4 to $2 \mathrm{~mL} / \mathrm{cm} \mathrm{H}_{2} \mathrm{O}$ (full-term) and from 2 to $1 \mathrm{~mL} / \mathrm{cm} \mathrm{H}_{2} \mathrm{O}$ (pre-term). To simulate obstructive disease, resistance was modified from 70 to $200 \mathrm{~cm} \mathrm{H}_{2} \mathrm{O} / \mathrm{L} / \mathrm{s}$ (fullterm) and from 100 to $200 \mathrm{~cm} \mathrm{H}_{2} \mathrm{O} / \mathrm{L} / \mathrm{s}$ (pre-term). To evaluate the effectiveness of the volume-targeted mode in maintaining the desired $\mathrm{V}_{\mathrm{T}}$, the test series was repeated with the volume-targeted mode activated in 3 of the ventilators offering this option. We used a targeted $V_{T}$ of $4 \mathrm{~mL}$ under full-term settings and $1 \mathrm{~mL}$ under pre-term infant settings. These target tidal volumes during oscillation have been chosen based on our own clinical observations (with most often observed $\mathrm{V}_{\mathrm{T}}$, which resulted in 
normocapnia, in the range $0.5-1.5 \mathrm{~mL} / \mathrm{kg}$ body weight at an oscillation frequency of $15 \mathrm{~Hz}$ ) over the years with the use of the SensorMedics 3100A device in combination with a neonatal respiratory monitor (Florian). The Florian has been validated for $\mathrm{V}_{\mathrm{T}}$ measurements during HFOV by Scalfaro et al. ${ }^{13}$

\section{Results}

\section{Influence of the Ventilator Properties on Delivered $\mathbf{V}_{\mathrm{T}}$ (Volume-Targeted Mode Inactivated)}

While simulating full-term infant conditions, all ventilators demonstrated a linear increase of the $\mathrm{V}_{\mathrm{T}}$ at 5 and $10 \mathrm{~Hz}$ following $\Delta \mathrm{P}_{\text {vent }}$ increase (Fig. 2A). However, at $15 \mathrm{~Hz}$ and a $\Delta \mathrm{P}_{\text {vent }}$ set at $60 \mathrm{~cm} \mathrm{H}_{2} \mathrm{O}$, we observed heterogeneity in the delivered $\mathrm{V}_{\mathrm{T}}$, which ranged from 2.6 to $6.3 \mathrm{~mL}$. In particular, the Babylog VN500 was unable to increase the $\mathrm{V}_{\mathrm{T}}$ because $\Delta \mathrm{P}_{\text {vent }}$ could not be increased beyond $36 \mathrm{~cm} \mathrm{H}_{2} \mathrm{O}$ at this oscillation frequency. While simulating pre-term infant conditions, we observed larger variability in the delivered $\mathrm{V}_{\mathrm{T}}$ between devices (Fig. 2B), in particular at $15 \mathrm{~Hz}$, with $\mathrm{V}_{\mathrm{T}}$ ranging from 3.5 to $5.9 \mathrm{~mL}$ with a pressure amplitude set at $60 \mathrm{~cm} \mathrm{H}_{2} \mathrm{O}$. Again, the Babylog VN500 delivered lower $\mathrm{V}_{\mathrm{T}}$ at $5 \mathrm{~Hz}$ and $15 \mathrm{~Hz}$ than the other ventilators and was unable to increase its maximal $\Delta \mathrm{P}_{\text {vent }}$ beyond $55 \mathrm{~cm} \mathrm{H}_{2} \mathrm{O}$ at a frequency of $10 \mathrm{~Hz}$ and beyond $33 \mathrm{~cm} \mathrm{H}_{2} \mathrm{O}$ at a frequency of $15 \mathrm{~Hz}$. Notably, the performance of the Babylog VN500 was unaffected by the type of the ventilator circuit used: Fisher Paykel Health- care or Hyrtel (Dräger Medical), the latter being the only one recommended by the manufacturer.

\section{Effect of Lung Mechanical Proprieties on Delivered $\mathbf{V}_{\mathbf{T}}$}

When compliance was changed from 4 to $2 \mathrm{~mL} / \mathrm{cm}_{2} \mathrm{O}$ in full-term infant setting (Table 2), delivered $\mathrm{V}_{\mathrm{T}}$ remained similar in all the ventilators and for all the frequencies tested, except for $15 \mathrm{~Hz}$. At $15 \mathrm{~Hz}$, the Babylog VN500 and the Leoni Plus responded to a decrease in compliance by an increase of the delivered $\mathrm{V}_{\mathrm{T}}$. In pre-term infant settings (Table 3), a compliance change from 2 to $1 \mathrm{~mL} / \mathrm{cm} \mathrm{H}_{2} \mathrm{O}$ at $5 \mathrm{~Hz}$ resulted in a decrease in $\mathrm{V}_{\mathrm{T}}$, whereas at $15 \mathrm{~Hz}$, the $\mathrm{V}_{\mathrm{T}}$ remained similar for all the ventilators with the exception of the Fabian HFO (which increased its $\mathrm{V}_{\mathrm{T}}$ ). The increase in resistance both in pre-term and fullterm infant settings resulted in a decrease of the delivered $\mathrm{V}_{\mathrm{T}}$ for all the ventilators, regardless of compliance.

\section{Influence of Volume-Targeted Mode on $\mathbf{V}_{\mathrm{T}}$ After Modification of Lung Mechanical Properties}

While simulating a full-term infant at 5 and $10 \mathrm{~Hz}$ and with a volume target set at $4 \mathrm{~mL}$, all 3 ventilators compensated for changes in compliance and resistance and kept the targeted volume constant (Fig. 3A). However, at $15 \mathrm{~Hz}$, none of the ventilators could fully compensate for the increase in resistance, resulting in a substantial loss of $\mathrm{V}_{\mathrm{T}}$. While simulating a pre-term infant, with a targeted
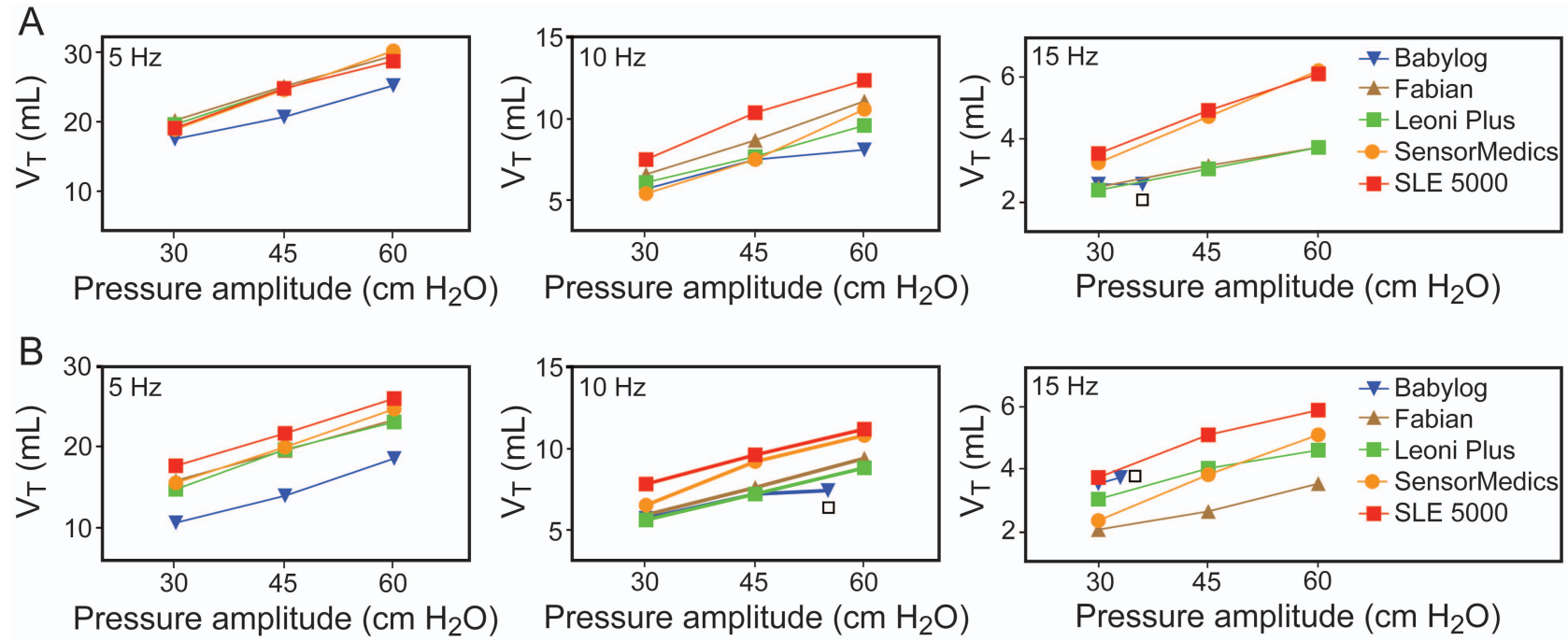

Fig. 2. Delivered tidal volume $\left(V_{T}\right)$ with various pressure amplitudes and oscillation frequencies in $A$ : full-term infant settings and $B$ : pre-term infant settings. Five ventilators were compared: Babylog VN500, Fabian HFO, Leoni Plus, SensorMedics, and SLE 5000, using the same mean airway pressure setting of $15 \mathrm{~cm} \mathrm{H}_{2} \mathrm{O}$ and I:E of $1: 1$. Note that, at a frequency of $15 \mathrm{~Hz}$ under full-term infant settings, the Babylog VN500 was not able to increase the pressure amplitude beyond $36 \mathrm{~cm} \mathrm{H} \mathrm{H}_{2} \mathrm{O}$ (white marker); under pre-term infant settings, the maximal pressure amplitudes delivered by the Babylog VN500 at $10 \mathrm{~Hz}$ and $15 \mathrm{~Hz}$ were $55 \mathrm{~cm} \mathrm{H}_{2} \mathrm{O}$ and $33 \mathrm{~cm} \mathrm{H}_{2} \mathrm{O}$, respectively (white markers). 
Table 2. Tidal Volume Variation After Change in Lung Condition Under Full-Term Infant Settings

\begin{tabular}{|c|c|c|c|c|}
\hline Ventilator & $\begin{array}{c}\text { Frequency } \\
\text { Rates } \\
(\mathrm{Hz})\end{array}$ & $\begin{array}{c}\text { Compliance } \\
\text { Decrease } \\
\left(\% \mathrm{~V}_{\mathrm{T}}\right. \\
\text { change })\end{array}$ & $\begin{array}{c}\text { Resistance } \\
\text { Increase } \\
\left(\% \mathrm{~V}_{\mathrm{T}}\right. \\
\text { change })\end{array}$ & $\begin{array}{r}\text { Combine } \\
\left(\% \mathrm{~V}_{\mathrm{T}}\right. \\
\text { change })\end{array}$ \\
\hline \multicolumn{5}{|c|}{ Babylog VN500 } \\
\hline & 5 & -5.5 & -66.5 & -68.1 \\
\hline & 10 & 0.0 & -62.1 & -63.2 \\
\hline & 15 & 80.0 & -48.0 & -32.0 \\
\hline \multicolumn{5}{|l|}{ SensorMedics } \\
\hline & 5 & 1.1 & -72.8 & -73.5 \\
\hline & 10 & 2.5 & -70.4 & -70.4 \\
\hline & 15 & 3.6 & -66.7 & -64.3 \\
\hline \multicolumn{5}{|l|}{ Leoni Plus } \\
\hline & 5 & -4.4 & -66.7 & -67.3 \\
\hline & 10 & 0.0 & -64.0 & -65.8 \\
\hline & 15 & 52.3 & -59.1 & -52.3 \\
\hline \multicolumn{5}{|l|}{ Fabian HFO } \\
\hline & 5 & -1.4 & -69.2 & -69.9 \\
\hline & 10 & 3.8 & -66.3 & -66.3 \\
\hline & 15 & 5.9 & -55.9 & -64.7 \\
\hline \multicolumn{5}{|l|}{ SLE 5000} \\
\hline & 5 & 2.3 & -69.1 & -69.5 \\
\hline & 10 & -2.4 & -61.8 & -62.9 \\
\hline & 15 & 6.7 & -61.3 & -58.7 \\
\hline
\end{tabular}

Results are presented as percentage of variation in tidal volume $\left(\mathrm{V}_{\mathrm{T}}\right)$ when the test lung compliance was decreased from 4 to $2 \mathrm{ml} / \mathrm{cm} \mathrm{H}_{2} \mathrm{O}$, the resistance increased from 70 to $200 \mathrm{~cm} \mathrm{H}_{2} \mathrm{O} / \mathrm{L} / \mathrm{s}$, or when both compliance and resistance were changed. Mean airway pressure was set at $15 \mathrm{~cm} \mathrm{H}_{2} \mathrm{O}$ with an I:E of 1:1 and maximal pressure amplitude.

volume of $1 \mathrm{~mL}$, all 3 ventilators compensated for changes in lung compliance and resistance and delivered the targeted $\mathrm{V}_{\mathrm{T}}$ when the frequency was set at $15 \mathrm{~Hz}$ (Fig. 3B). However, below $15 \mathrm{~Hz}$, all the ventilators delivered a $\mathrm{V}_{\mathrm{T}}$ that was higher than the pre-set $1 \mathrm{~mL}$.

\section{Discussion}

We observed large variability in performance between the ventilators, in particular at high oscillatory frequency (ie, $15 \mathrm{~Hz}$ ). The activation of the volume-targeted mode in pre-term infant settings allowed the $\mathrm{V}_{\mathrm{T}}$ to remain constant, although not always matching the set $\mathrm{V}_{\mathrm{T}}$, during changes of the respiratory system mechanical properties.

As shown previously, ${ }^{6-8,14}$ the principal factors influencing the mechanical performance of HFOV ventilators are frequency, inspiratory time, and load charge. Although all ventilators delivered lower $\mathrm{V}_{\mathrm{T}}$ with increasing frequencies, there were marked differences in the extent of $\mathrm{V}_{\mathrm{T}}$ decrease between ventilators at an oscillatory frequency of $15 \mathrm{~Hz}$. Indeed, the new generation of neonatal HFOV ventilators (Babylog VN500, Fabian HFO, and Leoni Plus) delivered lower $\mathrm{V}_{\mathrm{T}}$ than the $3100 \mathrm{~A}$ and SLE 5000 with the
Table 3. Tidal Volume Variation After Change in Lung Condition Under Preterm Infant Settings

\begin{tabular}{|c|c|c|c|c|}
\hline Ventilator & $\begin{array}{l}\text { Frequency } \\
\text { rates }(\mathrm{Hz})\end{array}$ & $\begin{array}{c}\text { Compliance } \\
\text { decrease } \\
\left(\% \mathrm{~V}_{\mathrm{T}}\right. \\
\text { change })\end{array}$ & $\begin{array}{c}\text { Resistance } \\
\text { increase } \\
\left(\% \mathrm{~V}_{\mathrm{T}}\right. \\
\text { change })\end{array}$ & $\begin{array}{c}\text { Combined } \\
\left(\% \mathrm{~V}_{\mathrm{T}}\right. \\
\text { change })\end{array}$ \\
\hline \multicolumn{5}{|l|}{ Babylog VN500 } \\
\hline & 5 & -12.0 & -60.6 & -61.0 \\
\hline & 10 & 1.3 & -57.3 & -58.7 \\
\hline & 15 & 5.4 & -54.1 & -56.8 \\
\hline \multicolumn{5}{|l|}{ SensorMedics } \\
\hline & 5 & -17.0 & -66.0 & -66.9 \\
\hline & 10 & 2.8 & -66.0 & -61.7 \\
\hline & 15 & 8.1 & -59.5 & -59.5 \\
\hline \multicolumn{5}{|l|}{ Leoni Plus } \\
\hline & 5 & -9.0 & -61.3 & -62.4 \\
\hline & 10 & 0.0 & -62.1 & -61.2 \\
\hline & 15 & 1.9 & -61.1 & -61.1 \\
\hline \multicolumn{5}{|l|}{ Fabian HFO } \\
\hline & 5 & -13.3 & -65.5 & -63.1 \\
\hline & 10 & -1.0 & -65.3 & -61.4 \\
\hline & 15 & 57.1 & -57.1 & -35.7 \\
\hline \multicolumn{5}{|l|}{ SLE 5000} \\
\hline & 5 & -4.7 & -58.5 & -60.1 \\
\hline & 10 & -0.7 & -56.6 & -57.9 \\
\hline & 15 & 5.9 & -54.4 & -54.4 \\
\hline
\end{tabular}

Results are presented as percentage of variation in tidal volume $\left(\mathrm{V}_{\mathrm{T}}\right)$ when the test lung compliance was decreased from 2 to $1 \mathrm{ml} / \mathrm{cm} \mathrm{H}_{2} \mathrm{O}$, when the resistance was increased from 100 to $200 \mathrm{~cm} \mathrm{H}_{2} \mathrm{O} / \mathrm{L} / \mathrm{s}$, or when both compliance and resistance were changed. Mean airway pressure was set at $15 \mathrm{~cm} \mathrm{H}_{2} \mathrm{O}$ with an I:E of 1:1 and maximal pressure amplitude.

same pressure amplitude settings, both under pre-term infant and full term infant settings. As the $\mathrm{CO}_{2}$ elimination during $\mathrm{HFOV}$ is proportional to $\mathrm{f} \cdot \mathrm{V}_{\mathrm{T}},{ }^{2,15,16}$ the difference in performance observed under our test conditions may be even more significant in clinical settings.

There is no consensus about the ideal $\mathrm{V}_{\mathrm{T}}$ for HFOV, but studies in animals ${ }^{17,18}$ and pre-term neonates ${ }^{19}$ have shown that a $\mathrm{V}_{\mathrm{T}}$ of 2-3 $\mathrm{mL} / \mathrm{kg}$ allows optimal gas exchange during HFOV. Although the use of these new generation neonatal ventilators is intended for the neonatal population unlike the 3100A (a ventilator that can be used with patients larger than neonates), some of them might not have sufficient power to deliver required $\mathrm{V}_{\mathrm{T}}$ for adequate gas exchange, especially when used in full-term infants at high oscillatory frequencies.

Differences in the new HFOV ventilator design limiting maximal oscillatory flows may account for the variability in performance observed in conditions characterized by reduced flows toward the patient (ie, at higher frequencies and lower inspiratory time). The SLE 5000, whose operating principle includes a continuous bias flow with 3 opposing jet flows, was the most powerful neonatal ventilator in term of volume delivery, with a performance 

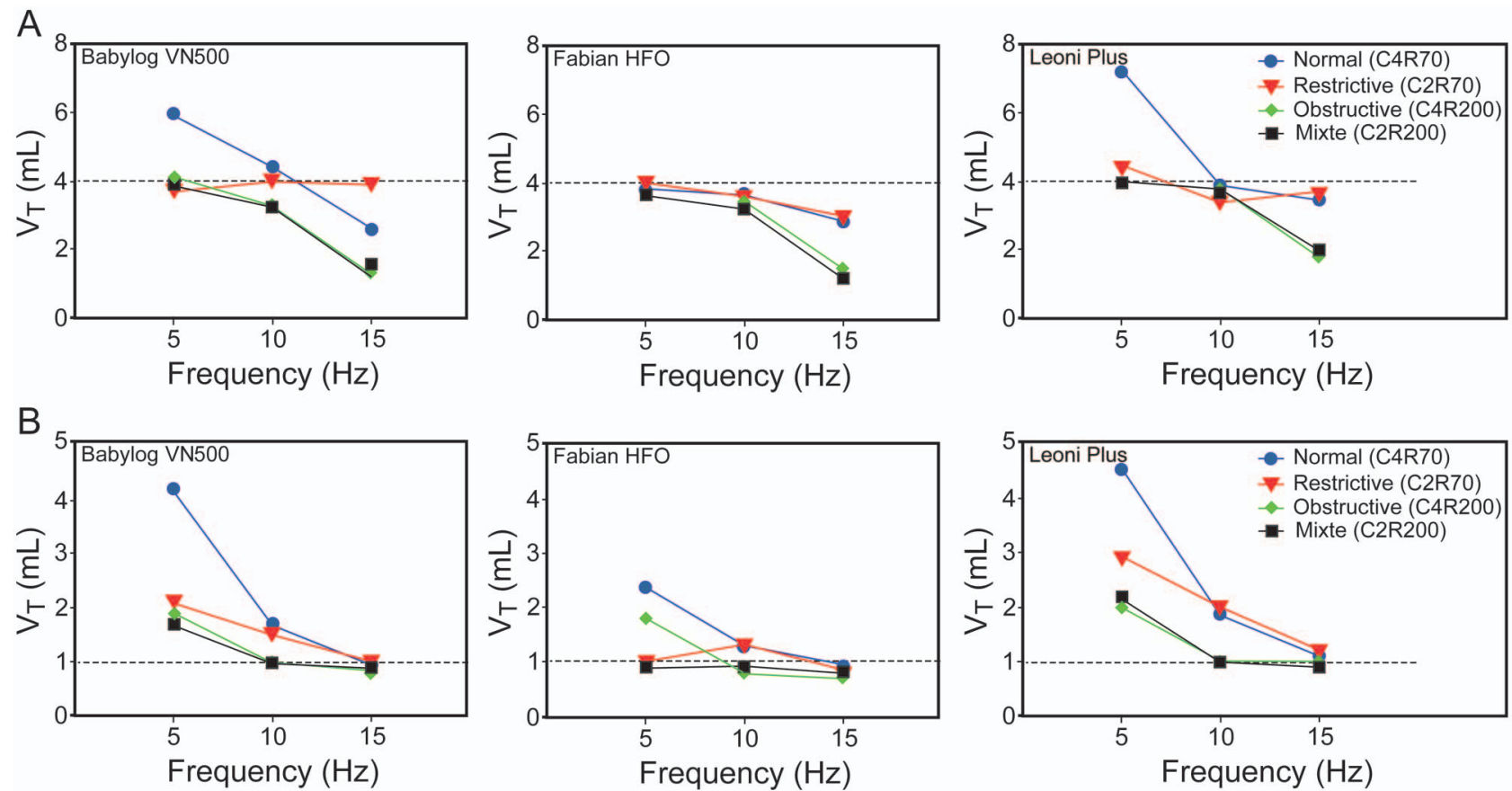

Fig. 3. Tidal volume $\left(V_{T}\right)$ responses to change in oscillation frequencies, lung compliance, and resistance after activation of the volumetargeted mode in A: full-term and B: pre-term infant settings. Three ventilators were compared: Babylog VN500, Fabian HFO, and the Leoni Plus, using the same mean airway pressure setting of $15 \mathrm{~cm} \mathrm{H} \mathrm{H}_{2} \mathrm{O}$, I:E of 1:1, and the maximal setting for oscillatory pressure limitation. The $\mathrm{V}_{\mathrm{T}}$ target was set at $4 \mathrm{~mL}$ under full-term infant settings and $1 \mathrm{~mL}$ under pre-term infant settings. $\mathrm{C}=$ compliance; $\mathrm{R}=$ resistance

similar to the 3100A. On the other hand, the Babylog VN500 presented important oscillatory flow limitations at high frequency settings as has also been reported in a recent bench study by John et al, ${ }^{9}$ and these were similar to those seen in the older Babylog 8000.6,7 This feature may be explained by the specific design of the Babylog VN500 that incorporates some of the technical concepts of the Babylog 8000 (ie, a Venturi multi-valve system on the expiratory side) combined with a new pulsed inspiratory flow. Because the flow is set automatically based on the frequency and the $\overline{\mathrm{P}}_{\mathrm{aw}}$, an insufficient bias flow may explain the power limitation of this ventilator seen in our study.

The use of volume target modes during conventional mechanical ventilation is well documented in neonates and has been shown to reduce the incidence of death, bronchopulmonary dysplasia, and severe intraventricular hemorrhage compared with pressure limited ventilation. ${ }^{20}$ Despite those obvious benefits, several reports demonstrated inaccuracies in the delivered $\mathrm{V}_{\mathrm{T}}$ during volume target ventilation with conventional mechanical ventilation with volume overshooting upon rapid change in respiratory mechanics. ${ }^{10,12}$

During HFOV, $\mathrm{V}_{\mathrm{T}}$ represents the principal determinant for $\mathrm{CO}_{2}$ removal and several reports found important fluctuation in the delivered $\mathrm{V}_{\mathrm{T}}$ during HFOV. ${ }^{21}$ In absence of direct $\mathrm{V}_{\mathrm{T}}$ monitoring on the old generation HFOV such as the SensorMedics 3100A, the clinician had to rely on the clinical exam as well as on repeated blood gas measurements to make changes in the ventilator settings which exposed the patients at risk for variation in $\mathrm{P}_{\mathrm{aCO}}$.

In this perspective, the incorporation of a flow sensor to measure $\mathrm{V}_{\mathrm{T}}$ into these new generation of neonatal HFOV represents a potentially useful improvement for the clinician although some inaccuracies in the measurements of $\mathrm{V}_{\mathrm{T}}$ has been reported. ${ }^{22} \mathrm{In}$ addition, the possibility to combine HFOV with a volume-targeted mode on these ventilators will keep $\mathrm{V}_{\mathrm{T}}$ constant after change in lung mechanics as demonstrated recently in an animal model of surfactant deficiency. ${ }^{5}$

The activation of the volume-targeted mode under high resistance conditions allowed the ventilators to maintain constant small targeted $\mathrm{V}_{\mathrm{T}}(1 \mathrm{~mL})$ but failed to maintain larger targeted $\mathrm{V}_{\mathrm{T}}(4 \mathrm{~mL})$ at $15 \mathrm{~Hz}$. Furthermore, at lower frequencies with a lower target $\mathrm{V}_{\mathrm{T}}$ of $1 \mathrm{~mL}$, all 3 ventilators delivered a higher-than-set $\mathrm{V}_{\mathrm{T}}$. Although there might theoretically be some potential advantages of using a guaranteed volume during HFOV, especially for small preterm neonates, some precautions must be taken when this option is activated at a low frequency with a small $\mathrm{V}_{\mathrm{T}}$ setting, as it may result in undesired overventilation for very small pre-term babies. Therefore, experimental stud- 
ies are needed to rule out our concerns before clinical studies can be conducted to determine the real utility of this new mode.

The primary limitation of our study is the experimental setup, which differs from the previous bench evaluation of neonatal HFOV ventilators. ${ }^{6,8,23}$ First, we used a test lung with airway resistance simulated using different sized airway resistors. This system allowed us to test different changes in respiratory mechanics but cannot completely reproduce the complexity of the neonatal respiratory system. Second, the delivered $\mathrm{V}_{\mathrm{T}}$ was directly measured using a hot-wire flow sensor, which may have added further resistance and could have attenuated the $\mathrm{V}_{\mathrm{T}}$ delivered by the ventilators. Although this might have induced a measurement bias, it could only be very small, because the resistance of the Florian anemometer is only $0.55 \mathrm{~Pa} / \mathrm{mL}$ with a $\dot{\mathrm{V}}$ of $100 \mathrm{~mL} / \mathrm{s}$, which would result theoretically in an additional reduction in $\mathrm{V}_{\mathrm{T}}$ of only $0.3 \mathrm{~mL} .13$

The record of single manual measurements on single ventilators constitutes another limitation, which may have affected the accuracy of the results. However, the record of measurements after 1 min steady state and the use of functional ventilators provided by their respective manufacturer and tested as per manufacturers' protocol before each test series helped to reduce the impact of these limitations on the different ventilators' characteristics described in this study. Because of these limitations, our results might not be directly applied to the clinical setting but emphasize the need for further clinical and animal studies to evaluate the performance and ventilation efficiency of the new generation neonatal HFOV ventilators.

In summary, all of the new generation neonatal HFOV ventilators can deliver adequate oscillation $\mathrm{V}_{\mathrm{T}}(1 \mathrm{~mL} / \mathrm{kg})$ under bench test conditions simulating various respiratory system mechanics of a pre-term infant, and do keep the $\mathrm{V}_{\mathrm{T}}$ constant in various respiratory system conditions upon activation of the volume-targeted mode. However, not all of the ventilators could deliver adequate oscillation $\mathrm{V}_{\mathrm{T}}$ $(4 \mathrm{~mL} / \mathrm{kg}$ ) for term infant conditions. Furthermore, there was heterogeneity between devices in the $\mathrm{V}_{\mathrm{T}}$ delivery at higher frequencies. Therefore, further studies are needed to determine the clinical importance of our findings from the bench.

\section{ACKNOWLEDGMENTS}

We thank Gustavo Matute-Bello MD (Division of Pulmonary \& Critical Care Medicine, University of Washington, Seattle, Washington) for the review of this manuscript and the useful comments he made.

\section{REFERENCES}

1. Cools F, Henderson-Smart DJ, Offringa M, Askie LM. Elective high frequency oscillatory ventilation versus conventional ventilation for acute pulmonary dysfunction in preterm infants. Cochrane Database Syst Rev 2009;(3):CD000104.

2. Cools F, Askie LM, Offringa M, Asselin JM, Calvert SA, Courtney SE, et al. Elective high-frequency oscillatory versus conventional ventilation in preterm infants: a systematic review and meta-analysis of individual patients' data. Lancet 2010;375(9731): 2082-2091.

3. Courtney SE, Durand DJ, Asselin JM, Hudak ML, Aschner JL, Shoemaker CT. High-frequency oscillatory ventilation versus conventional mechanical ventilation for very-low-birth-weight infants. N Engl J Med 2002;347(9):643-652.

4. Salvo V, Zimmermann LJ, Gavilanes AW, Barberi I, Ricotti A, Abella R, et al. First intention high-frequency oscillatory and conventional mechanical ventilation in premature infants without antenatal glucocorticoid prophylaxis. Pediatr Crit Care Med 2012;13(1): 72-79.

5. Sanchez Luna M, Santos Gonzalez M, Tendillo Cortijo F. Highfrequency oscillatory ventilation combined with volume guarantee in a neonatal animal model of respiratory distress syndrome. Crit Care Res Pract 2013;593915, 2013.

6. Jouvet P, Hubert P, Isabey D, Pinquier D, Dahan E, Cloup M, Harf A. Assessment of high-frequency neonatal ventilator performances. Intensive Care Med 1997;23(2):208-213.

7. Hatcher D, Watanabe H, Ashbury T, Vincent S, Fisher J, Froese A. Mechanical performance of clinically available, neonatal, highfrequency, oscillatory-type ventilators. Crit Care Med 1998;26(6): 1081-1088.

8. Pillow JJ, Wilkinson MH, Neil HL, Ramsden CA. In vitro performance characteristics of high-frequency oscillatory ventilators. Am J Respir Crit Care Med 2001;164(6):1019-1024.

9. John J, Harcourt ER, Davis PG, Tingay DG. Drager VN500's oscillatory performance has a frequency-dependent threshold. J Paediatr Child Health 2014;50(1):27-31.

10. Abubakar KM, Keszler M. Patient-ventilator interactions in new modes of patient-triggered ventilation. Pediatr Pulmonol 2001;32(1): 71-75.

11. Lista G, Colnaghi M, Castoldi F, Condo V, Reali R, Compagnoni G, Mosca F. Impact of targeted-volume ventilation on lung inflammatory response in preterm infants with respiratory distress syndrome (RDS). Pediatr Pulmonol 2004;37(6):510-514.

12. Jaecklin T, Morel DR, Rimensberger PC. Volume-targeted modes of modern neonatal ventilators: how stable is the delivered tidal volume? Intensive Care Med 2007;33(2):326-335.

13. Scalfaro P, Pillow JJ, Sly PD, Cotting J. Reliable tidal volume estimates at the airway opening with an infant monitor during highfrequency oscillatory ventilation. Crit Care Med 2001;29(10):19251930.

14. Iguchi N, Hirao O, Uchiyama A, Mashimo T, Nishimura M, Fujino Y. Evaluation of performance of two high-frequency oscillatory ventilators using a model lung with a position sensor. J Anesth 2010; 24(6):888-892.

15. Rossing TH, Slutsky AS, Lehr JL, Drinker PA, Kamm R, Drazen JM. Tidal volume and frequency dependence of carbon dioxide elimination by high-frequency ventilation. N Engl J Med 1981;305(23): 1375-1379.

16. Slutsky AS, Kamm RD, Rossing TH, Loring SH, Lehr J, Shapiro $\mathrm{AH}$, et al. Effects of frequency, tidal volume, and lung volume on $\mathrm{CO} 2$ elimination in dogs by high frequency $(2-30 \mathrm{~Hz})$, low tidal volume ventilation. J Clin Invest 1981;68(6):1475-1484.

17. Harf A, Bertrand C, Chang HK. Ventilation by high-frequency oscillation of thorax or at trachea in rats. J Appl Physiol 1984;56(1): 155-160.

18. Kamitsuka MD, Boynton BR, Villanueva D, Vreeland PN, Frantz ID 3rd. Frequency, tidal volume, and mean airway pressure combina- 


\section{Neonatal HFov Device Performance}

tions that provide adequate gas exchange and low alveolar pressure during high frequency oscillatory ventilation in rabbits. Pediatr Res 1990;27(1):64-69.

19. Dimitriou G, Greenough A, Kavvadia V, Laubscher B, Milner AD. Volume delivery during high frequency oscillation. Arch Dis Child Fetal Neonatal Ed 1998;78(2):F148-150.

20. Morley CJ. Volume-limited and volume-targeted ventilation. Clin Perinatol 2012;39(3):513-523.

21. Zimova-Herknerova M, Plavka R. Expired tidal volumes measured by hot-wire anemometer during high-frequency oscillation in preterm infants. Pediatr Pulmonol 2006;41(5):428-433.

22. Abbasi S, Sivieri E, Roberts R, Kirpalani H. Accuracy of tidal volume, compliance, and resistance measurements on neonatal ventilator displays: an in vitro assessment. Pediatr Crit Care Med 2012; 13(4):e262-268.

23. Fredberg JJ, Glass GM, Boynton BR, Frantz ID 3rd. Factors influencing mechanical performance of neonatal high-frequency ventilators. J Appl Physiol 1987;62(6):2485-2490. 